\title{
THE
}

\section{Structure activity related, mechanistic, and modeling studies of gallotannins containing a glucitol-core and $\boldsymbol{\alpha}$-glucosidase}

\author{
Hang Ma \\ University of Rhode Island, hang_ma@uri.edu \\ Ling Wang \\ Daniel B. Niesen \\ University of Rhode Island \\ Ang Cai \\ University of Rhode Island \\ Bongsup P. Cho \\ University of Rhode Island, bpcho@uri.edu
}

See next page for additional authors

Follow this and additional works at: https://digitalcommons.uri.edu/bps_facpubs

This is a pre-publication author manuscript of the final, published article.

Terms of Use

All rights reserved under copyright.

\section{Citation/Publisher Attribution}

Ma, H., Wang, L., Niesen, D. B., Cai, A., Cho, B. P., Tan, W., Gu, Q.,...Seeram, N. P. (2015). Structure activity related, mechanistic, and modeling studies of gallotannins containing a glucitol-core and $\alpha$-glucosidase. RSC Adv., 5, 107904-107915. doi: 10.1039/C5RA19014B

Available at: http://dx.doi.org/10.1039/C5RA19014B

This Article is brought to you for free and open access by the Biomedical and Pharmaceutical Sciences at DigitalCommons@URI. It has been accepted for inclusion in Biomedical and Pharmaceutical Sciences Faculty Publications by an authorized administrator of DigitalCommons@URI. For more information, please contact digitalcommons-group@uri.edu. 


\section{Authors}

Hang Ma, Ling Wang, Daniel B. Niesen, Ang Cai, Bongsup P. Cho, Wen Tan, Qiong Gu, Jun Xu, and Navindra P. Seeram 


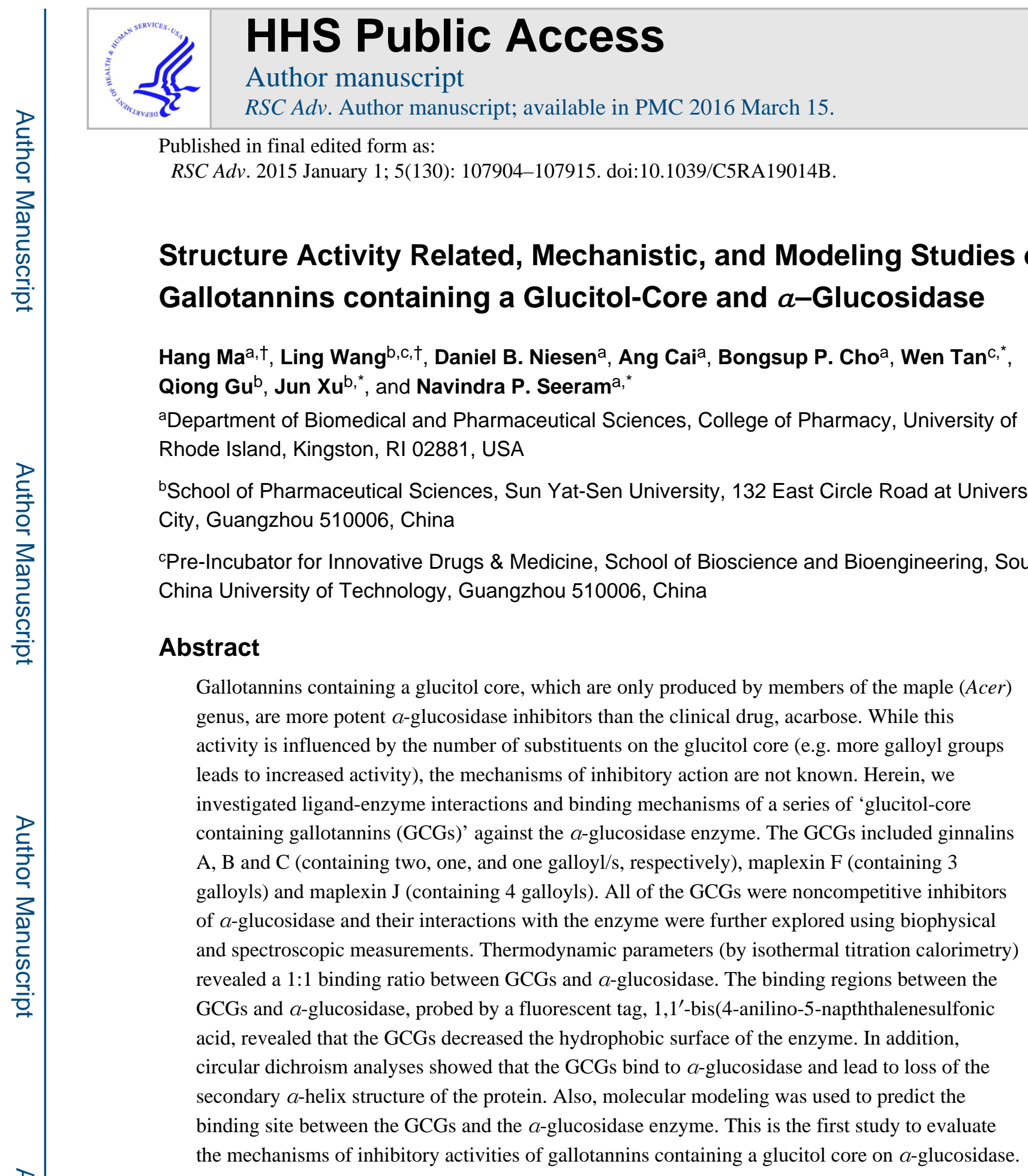

\section{Graphical abstract}

*Authors to whom correspondence should be addressed: N.P.S.: Phone/Fax: 401-874-9367/5787, nseeram@.uri.edu. J.X.: Phone: 86-20-3994-3023, xujun9@mail.sysu.edu.cn.W.T.: Phone: 86-20-3938-0669, wentan@scut.edu.cn.

$\dagger$ Equal contribution.

Conflicts of interest

The authors have declared no conflicts of interest. 


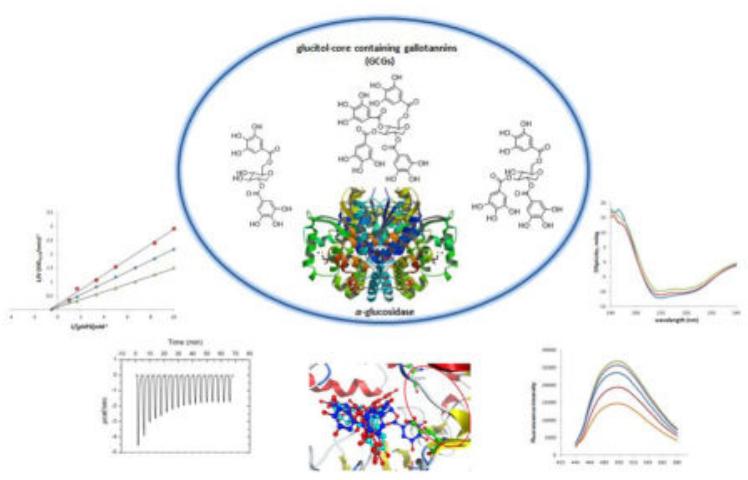

Evaluation of the mechanisms of inhibitory activities of gallotannins containing a glucitol core (GCGs) on $a$-glucosidase.

\section{Keywords}

glucitol-core containing gallotannins (GCGs); maple; $a$-glucosidase inhibition; isothermal titration calorimetry (ITC); computational modeling

\section{INTRODUCTION}

In mammals, enzymes involved in the carbohydrate metabolic pathways have been the therapeutic targets for various diseases, including diabetes, cancer, and viral infections. ${ }^{1-3}$ Among these enzymes, the group of glucosidases (EC 3.2.1.20) plays a crucial role in carbohydrate metabolism by catalyzing the cleavage of glycosidic linkages of oligosaccharides or glycoconjugates to release mono-saccharides. ${ }^{4}$ Inhibition of glucosidase hinders glucose absorption and consequently decreases postprandial blood glucose levels. Development of $a$-glucosidase inhibitors, as a class of antidiabetic medications for type II diabetes mellitus (T2DM), has attracted significant scientific attention. ${ }^{5}$ In fact, several synthetic $\alpha$-glucosidase inhibitors (AGIs), including acarbose, miglitol, and voglibose, are widely used as clinical treatment options for T2DM. ${ }^{6,7}$ However, adherence to synthetic AGIs, as prescription medications, has suffered due to prominent undesirable adverse effects, including flatulence, diarrhea, and abdominal pain. ${ }^{8}$ In addition, the adult dose of some AGIs, for instance, acarbose, can range from $25-100 \mathrm{mg}$ taken orally 3 times daily. Therefore, the utilization of natural products represents an attractive alternative to clinical drugs since they may lead to increased patient compliance. Moreover, naturally occurring AGIs, isolated from medicinal plants and medicinal foods, offer an attractive dietary strategy for T2DM management since they tend to be safe, and have fewer adverse effects than synthetic AGIs. ${ }^{9}$

The maple (Acer) genus is widely regarded for certain species including the sugar maple (Acer saccharum) and red maple (Acer rubrum) species, the sap of which are collected and concentrated to produce the natural sweetener, maple syrup. ${ }^{10}$ Interestingly, in the plant kingdom, only members of the maple (Acer) genus are reported to produce gallotannins containing a glucitol instead of a glucose core which is most commonly found in 
gallotannins. ${ }^{11-16}$ Our group and others have shown that these 'glucitol-core containing gallotannins (GCGs)' display potent $a$-glucosidase inhibitory properties which is influenced by the number, type, and location of substituents on their glucitol core. ${ }^{14-17}$ In addition, our group showed that a red maple bark extract, enriched in GCGs, was similar in activity as acarbose, in lowering blood glucose in an animal model. ${ }^{18}$ Therefore GCGs represent an interesting polyphenol sub-class of plant natural products which show great promise as natural AGIs.

In our group's research efforts to identify natural AGIs, we reported on a series of new GCGs, named maplexins E-I, from the red maple (Acer rubrum) species. ${ }^{14-16}$ The GCGs feature different numbers and positions of galloyl groups attached to a 1,5-anhydro-Dglucitol core and exhibited 20-fold higher potency than acarbose which increased with the number of galloyl groups on the glucitol moiety. However, since these naturally occurring/ isolated GCGs only contained three galloyl groups at the most, in an effort to broaden our test panel of GCGs, we synthesized a tetragalloylglucitol analog ${ }^{19}$ (details provided in Online Supplementary Material) assigned the common name of maplexin J. Indeed, maplexin $\mathbf{J}$ was found to be three times more potent than maplexins $\mathrm{E}$ and $\mathrm{F}$ (contain trigalloyls), and 70 times more potent than acarbose (see Table 1), confirming our previous SAR observations. In the current study, we have focused our attention on investigating the mechanisms of inhibitory actions of these GCGs on the $a$-glucosidase enzyme. This research project was also prompted, in part, by the fact that other natural AGIs, such as 1deoxynojirimycin, resveratrol, and oxyresveratrol, show different mechanisms of action against $a$-glucosidase..$^{20,21}$

The mechanisms of inhibition of compounds on the $\alpha$-glucosidase enzyme can be investigated by several biophysical methods including binding domains, modifications of hydrophobic surfaces, and secondary structural conformational changes of enzymes induced by binding ligands. ${ }^{21}$ In this study, enzymatic kinetics and biophysical tools, including isothermal titration calorimetry (ITC), fluorescence, and circular dichroism (CD) spectroscopic methods, were used to elucidate the inhibitory mechanisms of the GCGs against the $\alpha$-glucosidase enzyme. Computational manipulation of homology modeling and molecular docking were performed to support the prediction of binding actions between the GCGs and the $\alpha$-glucosidase enzyme.

\section{EXPERIMENTAL SECTION}

\section{Chemicals}

$a$-Glucosidase (EC 3.2.1.20) from Saccharomyces cerevisiae, p-Nitrophenyl- $a$-Dglucopyranoside (pNPG), and bis-8-anilinonaphthalene-1-sulfonate (bis-ANS) were purchased from Sigma Aldrich (St. Louis, MO). All other chemicals were analytical reagent grade and were purchased from Sigma Aldrich, unless otherwise specified. The naturally occurring GCGs (Figure 1): ginnalin A (GA; contains two galloyls), ginnalin B (GB; contains one galloyl), ginnalin C (GC; contains one galloyl) and maplexin F (MF; contains three galloyls) were isolated from the red maple species as previously reported. ${ }^{14,15}$ Maplexin J (MJ; contains four galloyls) was synthesized in our laboratory according to 
modifications of a previously published method ${ }^{19}$ [details provided in Online Supporting Material].

\section{Measurements of $a$-glucosidase inhibitory assay}

A mixture of $50 \mu \mathrm{L}$ test samples and $100 \mu \mathrm{L} 0.1 \mathrm{M}$ phosphate buffer (pH 6.9) containing yeast $a$-glucosidase solution $(1.0 \mathrm{U} / \mathrm{ml})$ were incubated in 96 -well plates at $25^{\circ} \mathrm{C}$ for 10 minutes. After pre-incubation, $50 \mu \mathrm{L}$ of $5 \mathrm{mM}$ p-nitrophenyl- $\alpha$-D-glucopyranoside solution in $0.1 \mathrm{M}$ phosphate buffer ( $\mathrm{pH}$ 6.9) were added to each well at timed intervals. The reaction mixtures were incubated at $25{ }^{\circ} \mathrm{C}$ for 5 minutes. Before and after incubation, absorbance was recorded at $405 \mathrm{~nm}$ by a micro-plate reader (SpectraMax M2, Molecular Devices Corp., operated by SoftmaxPro v.4.6 software, Sunnyvale, CA) and compared to that of the control which had $50 \mu \mathrm{L}$ buffer solutions in place of the samples. The $\alpha$-glucosidase inhibitory activity was expressed as inhibition \% and was calculated as: Inhibition\% $=100 \times\left[\left(\mathrm{C}_{5}-\right.\right.$ $\left.\left.\mathrm{C}_{0}\right)-\left(\mathrm{S}_{0}-\mathrm{S}_{0}\right)\right] /\left(\mathrm{C}_{5}-\mathrm{C}_{0}\right)$, where $\mathrm{C}_{0}$ is the absorbance of the reagent blank in 0 minute, $\mathrm{S}_{0}$ the absorbance of the samples in 0 minute, $\mathrm{C}_{5}$ the absorbance of the reagent blank in 5 minutes, and $\mathrm{S}_{5}$ the absorbance of the samples in 5 minutes. ${ }^{22}$

\section{Kinetics of $a$-glucosidase inhibition}

The inhibition types of ginnalin A (GA), maplexin F (MF), and maplexins J (MJ) were determined from Lineweaver-Burk plots, using previously reported methods with minor modifications. ${ }^{23}$ Typically, two concentrations around the $\mathrm{IC}_{50}$ values of each sample were chosen (ranging from $2-250 \mu \mathrm{M}$ ). For each concentration, $\alpha$-glucosidase activities were tested by using different concentrations of pPNP glycoside (1 to $1000 \mu \mathrm{M})$. The mixtures of the enzyme and the inhibitor were dissolved in $50 \mathrm{mM}$ phosphate buffer ( $\mathrm{pH} 6.8$ ), and preincubated at room temperature for 30 minutes, and then the substrate was added. The enzymatic reaction was carried out at room temperature for 60 seconds, and monitored spectrophotometrically by measuring the absorbance at $405 \mathrm{~nm}$. Inhibition types of the inhibitors were determined by Double-reciprocal plots.

\section{Titration microcalorimetry}

Isothermal titration calorimetry (ITC), used to determine the thermodynamic properties between the GCGs and $\alpha$-glucosidase, were measured with a VP-ITC

Microcalorimeter (MicroCal, Northampton, MA, USA) according to previously reported methods with modifications. ${ }^{24} \mathrm{~A}$ typical titration experiment consisted of 17 consecutive injections at $240 \mathrm{~s}$ intervals consisting of $14 \mu \mathrm{L}$ injections of each GCGs into the titration cell at $25{ }^{\circ} \mathrm{C}$ in phosphate buffer $(\mathrm{pH} 7.0,100 \mathrm{mM})$. The titration cell was stirred continuously at $310 \mathrm{rpm}$. The GCGs $(1-4 \mathrm{mM})$ and $\alpha$-glucosidase enzyme $(0.026-0.031$ $\mathrm{mM}$ ) were dissolved in the same phosphate buffer and degassed for 20 mins under vacuum using a ThermoVac (MicroCal, Northampton, MA, USA) prior to each experiment. Controls included buffer injected into buffer and GCGs injected into buffer solutions, respectively. Data were analyzed by using nonlinear regression with a single-site binding model in VP Viewer 2000, which uses the scientific plotting software, ORIGIN 7 (Origin Lab. Corp., Northampton, MA, USA). 


\section{Hydrophobic interactions of $a$-glucosidase using bis-ANS}

$a$-glucosidase $(2 \mu \mathrm{M})$ was incubated in the presence of various concentrations of the GCGs $(0-80 \mu \mathrm{M})$ at $37{ }^{\circ} \mathrm{C}$ for 5 minutes. Bis-ANS $(5 \mu \mathrm{M})$ was then added, and fluorescence was measured after incubation at $37^{\circ} \mathrm{C}$ for 15 minutes $\left(\lambda_{\mathrm{ex}}=400 \mathrm{~nm}, \lambda_{\mathrm{em}}=440-600 \mathrm{~nm}\right) .{ }^{25}$

\section{Circular dichroism (CD) spectroscopy}

Far UV CD measurements (190-240 nm) were conducted on a Jasco J-810 spectropolarimeter equipped with a Peltier temperature controller at $25^{\circ} \mathrm{C}$. Briefly, $2 \mu \mathrm{M}$ of $a$-glucosidase was treated with various concentrations of the GCGs $(0-80 \mu \mathrm{M})$. The samples were dissolved in $200 \mu \mathrm{L}$ of a sodium phosphate buffer $(0.1 \mathrm{M}, \mathrm{pH} 6.8)$ and placed in a 1.0 $\mathrm{mm}$ path length cell. The spectra were collected and corrected by subtraction of a blank 0.1 $\mathrm{M}$ sodium phosphate buffer ( $\mathrm{pH}$ 6.8), reducing noise and smoothing. ${ }^{26}$ The changes of secondary structure of $a$-glucosidase were estimated according to a method in the DichroWeb program, an online server for protein secondary structure analyses from the CD spectroscopic data. $^{27,28}$

\section{Homology modeling of $a$-glucosidase}

The Saccharomyces cerevisiae $a$-glucosidase was downloaded from the UniProt protein knowledgebase (accession number P53341). ${ }^{29}$ The structure of isomaltase from Saccharomyces cerevisiae (PDB entry 3A4A) that shared a 71.8\% sequence identity and $87.1 \%$ sequence similarity with Saccharomyces cerevisiae $a$-glucosidase based on National Center for Biotechnology Information Basic Local Alignment Search Tool (NCBI BLAST) search results was selected as the template for homology modeling. Sequence alignment and structural model building were performed using DS 3.5 (Discovery Studio, version 3.5, Accelrys, Inc., San Diego, CA, USA). Ten initial 3D $a$-glucosidase structures were constructed and sorted in ascending order of PDF total energy score. The best structure with the most negative score was selected for further refinements.

\section{Refinement of 3D $a$-glucosidase structure}

Molecular dynamics (MD) simulation is widely used for both homology and X-ray structural refinement. ${ }^{30,31}$ The initial best 3D $a$-glucosidase structure from homology modeling was refined through MD simulations using Amber12. ${ }^{32}$ The initial structure was solvated in an octahedron periodic box (based on the TIP3P model) with $12 \AA$ of water along each dimension. The protein was applied with the Amber ff99SB force field and counterions were added to the system to neutralize charges. ${ }^{33}$

MD simulations consisted of energy minimization, heat phase, equilibration, and production. The solvated system was minimized by three steps. First, a harmonic constraint potential of $10 \mathrm{kcal} / \mathrm{mol} / \AA^{2}$ was applied to all atoms except water molecules. Second, the protein backbone atoms were restrained with a force of $5.0 \mathrm{kcal} / \mathrm{mol} / \AA^{2}$. Finally, all atoms were allowed to move freely. In each step, energy minimization was executed by the steepest descent method for the first 2000 steps and the conjugated gradient method for the subsequent 2000 steps. After minimization, the system was gradually heated in the canonical "NVT ensemble" from 0 to 300 Kelvin (K) in 100 picoseconds (ps) using a Langevin 
thermostat with a coupling coefficient of $1.0 \mathrm{ps}$ with a force constant $10 \mathrm{kcal} / \mathrm{mol} / \AA^{2}$ on the protein. The system was then equilibrated for the first two $500 \mathrm{ps}$ and subsequent three 200 ps at $300 \mathrm{~K}$ with decreasing restraint weights reduced from 10 to $0.2 \mathrm{kcal} / \mathrm{mol} / \AA^{2}$. A production simulation run for $10 \mathrm{~ns}$ was lastly performed at $300 \mathrm{~K}$. During the MD simulations, the long-range Coulombic interactions were handled using the particle mesh Ewald (PME) method and the cutoff distance for the long-range van der Waals (vdW) energy term was set at $10.0 \AA .{ }^{34}$ All hydrogen atoms were constrained using the "SHAKE" algorithm and the time step was set at 2 femtosecond. Coordinate trajectories were recorded every $2 \mathrm{ps}$. The refined 3D a-glucosidase structure was obtained from last snapshot of MD simulations and validated by Profiles-3D Verify module in DS 3.5.

\section{Molecular docking}

GA, MF, and MJ were optimized using MMFF94s force field. The refined a-glucosidase structure from MD simulations was protonated based on amber99 force field after removing water molecules. To obtain the most plausible binding sites, we searched the whole 3-D space of the receptors, including both the active-site (Asp214, Glu276 and Asp349) and nonactive-site regions. Site Finder module encoded in MOE (MOE 2010.10. Chemical Computing Group, Inc. Montreal, Canada) was employed for detecting potential ligand binding sites of a-glucosidase. MOE-docking was employed to identify the binding poses of GA, MF, MJ and a-glucosidase. During docking study, 30 poses per compound were retained. All docked poses of GA, MF, and MJ were ranked on the basis of the binding docking energies according to LondondG score. ${ }^{35,36}$ The best conformation for each compound from clustering results was chosen for binding mode analyses.

\section{RESULTS}

\section{Comparison of $a$-glucosidase inhibitory effects of GCGs}

As shown in Table 1, the inhibitory activities of the GCGs against the $\alpha$-glucosidase enzyme increased with increasing number of galloyl groups attached to the 1,5-anhydro-D-glucitol moiety. The mono-galloyl substituted gallotannins (GB and GC) did not demonstrate any inhibitory activities on $a$-glucosidase ( $\mathrm{IC}_{50}>1000 \mu \mathrm{M}$ ), and the di-galloyl gallotannin (GA) only showed a moderate inhibitory activity with an $\mathrm{IC}_{50}$ value of $216.43 \mu \mathrm{M}$. However, the activities of MF and MJ, which contain three and four galloyl groups, respectively, were significantly enhanced ( $\mathrm{IC}_{50}=13.70$ and $4.27 \mu \mathrm{M}$, respectively). The results indicated that $\mathrm{MF}$ and MJ were potent $\alpha$-glucosidase inhibitors.

To further evaluate the inhibitory characteristics of GA, MF and MJ, enzyme kinetic assays were performed and their inhibition types were determined by the Lineweaver-Burk plots (Figure 3). The Lineweaver-Burk plot of each GCG (at different concentrations ranging from $2-250 \mu \mathrm{M}$ ) generated straight lines that all intersected the $X$-axis at the same point, suggesting that the GCGs were typical noncompetitive inhibitors of $a$-glucosidase. Therefore, this implied that GA, MF, and MJ bind to the noncompetitive site of the yeast's $a$-glucosidase enzyme rather than to the catalytic domain of the enzyme. 


\section{ITC measurement}

The thermodynamic properties of the binding interaction between the GCGs and $a$ glucosidase complex were determined by using ITC. The titration peaks of GA, GB, and GC (at concentrations ranging from $1-4 \mathrm{mM}$ ) were too weak to yield thermodynamic parameters. However, the titration peaks for MF or MJ (concentrations ranging from $1-2$ $\mathrm{mM}$ ) showed binding interactions that were typically exothermic (see Figure 3 ). The thermodynamic parameters for GA, MF, and MJ, obtained from the ITC analyses, are summarized in Table 2. Both MF and MJ had a ligand:enzyme ratio ( $N$ value) of 1:1 indicating that one molecule of each of these GCGs binds to one molecule of the enzyme. ${ }^{37}$ In addition, the binding constants $\left(K_{a}\right)$ of MF or MJ with $\alpha$-glucosidase were $2.85 \times 10^{4}$ and $4.22 \times 10^{4} \mathrm{~mol}^{-1}$, respectively. The stronger binding affinity of MJ with $\alpha$-glucosidase, compared to that of MF and the enzyme, was in agreement with the results obtained from the $a$-glucosidase inhibitory assay with these GCGs (Table 1). ${ }^{38}$ The negative $\Delta G$ values for both MF and MJ (-6.09 and $-6.31 \mathrm{kcal} / \mathrm{mol}$, respectively) suggested that their binding interactions were spontaneous. ${ }^{38,39}$ Furthermore, a positive $\Delta S$ value and a negative $\Delta H$ value for both MF and MJ indicated that their binding interactions with the $a$-glucosidase enzyme were enthalpy-driven. ${ }^{39,}{ }^{40}$ Notably, the thermodynamic parameters observed for MF and MJ are similar to those reported for the major gallotannin present in tea, namely, epigallocatechin gallate (EGCG), with lipase. ${ }^{38}$

Given that a positive $\Delta S$ value may be associated with the first stage of binding interaction, ${ }^{41,42}$ where the ligand and enzyme are immobilized in a hydrophobic environment, we further examined the hydrophobic alteration of the $\alpha$-glucosidase enzyme.

\section{GCGs reduced the hydrophobicity of $a$-glucosidase}

Noncovalent fluorescent probes have been extensively used for the study of protein conformation. ${ }^{43,44}$ An external fluorescent probe such as bis-8-anilinonaphthalene-1sulfonate (bis-ANS) is sensitive to the protein microenvironment and selectively binds to the hydrophobic surface of protein. ${ }^{45}$ Therefore, a bis-ANS probe was utilized to assess the exposure of $a$-glucosidase hydrophobic surface induced by the ligands. As shown in Figure 4, after being co-incubated with $\alpha$-glucosidase for $20 \mathrm{~min}$ at $37^{\circ} \mathrm{C}, \mathrm{GA}, \mathrm{MF}$, and MJ were able to decrease the fluorescence of the bis-ANS-enzyme complex in a concentrationdependent manner. Although GA slightly decreased the fluorescent intensity of the bisANS-enzyme complex at the low concentration $(20 \mu \mathrm{M})$, compared to the non-treatment group, the fluorescence of the MF and MJ treatment groups were significantly reduced. Moreover, all three ligands greatly decreased the fluorescence at concentration of $80 \mu \mathrm{M}$, suggesting that GA, MF, and MJ could decrease the hydrophobic surfaces of $\alpha$-glucosidase. Since hydrophobic surface is crucial to facilitate the formation of the enzyme active site, GA, MF, and MJ could have possibly inhibited the $\alpha$-glucosidase enzyme activity by inducing poor hydrophobic surfaces on the enzyme structure. ${ }^{46}$

\section{Change in conformation of $a$-glucosidase induced by GCGs}

To further examine the effects of the GCGs on the secondary structure of $a$-glucosidase, circular dichroism (CD) spectra of free $\alpha$-glucosidase and ligand- $a$-glucosidase complex were acquired. In Figure 5, the CD spectra of the free $\alpha$-glucosidase enzyme exhibited two 
characteristic negative bands at 208 and $222 \mathrm{~nm}$, indicating that the major secondary protein structure presented in the $a$-glucosidase was $a$-helix. ${ }^{47,48}$ When various concentrations (20 $-80 \mu \mathrm{M})$ of the GCGs were co-incubated with $a$-glucosidase, the CD spectra of the ligandenzyme complex was significantly altered indicating that the conformation of the enzyme protein was affected by the ligands in a concentration-dependent manner. As summarized in Table 3, the GCGs bind to the enzyme protein that mainly resulted in the loss of $a$-helix conformation. When $40 \mu \mathrm{M}$ of MF and MJ were delivered to $a$-glucosidase, the enzyme lost 4.9 and $5.6 \%$ of its $a$-helix conformation, respectively, which could potentially cause the loss of biological functions of the $a$-glucosidase enzyme.

\section{Homology modeling}

Lacking the 3D structure of Saccharomyces cerevisiae $\alpha$-glucosidase used in biological assays, we constructed a 3D homology structure of $\alpha$-glucosidase by computational approach. The 3D homology models of $a$-glucosidase were generated with the MODELER module in DS 3.5, and the best model with lowest PDF total energy score was refined by 10ns MD simulations (Figure 6B). Trajectory-based analysis showed that the root-meansquare deviation (RMSD) of the protein backbone atoms with reference to the initial structural coordinates increased slowly in the first 4 nanoseconds (ns) and then subsequently stabilized after $4 \mathrm{~ns}$, suggesting that the $\alpha$-glucosidase structure was stable.

The refined structure from the last snapshot of MD simulations was validated via Profile-3D, Procheck, and Prostat analysis. The overall self-compatibility score generated by Profile-3D module in DS 3.5 for this refined model was 252.5 (the verified expected high score was 263.47, and the verified expected low score was 118.56). Procheck was used to calculate the $\varphi$ and $\psi$ angles (Figure 6A) and four residues (Ser331, Glu522, Arg543, and Tyr372) were located in un-allowed regions, and the percentage of residues within the Ramachandran plot's allowed regions was $99.32 \%$. Prostat analysis showed that almost all bond lengths, angles, and torsions stayed within a rational range. All of these validation results proved that the refined model is reliable.

\section{Binding modes analyses}

A total of 35 potential ligand binding sites of the refined model were obtained from Site Finder module in MOE. The largest five binding sites (size > 100) were selected for the docking study (Figure 6). As shown in Table 4, the three GCGs, namely, GA, MF, and MJ, shared the same scaffold, suggesting that they bind at the same site for a given target. Sites 2,4 , and 5 were not suitable for these compounds because the trends of the docking scores for GA, MF, and MJ were inconsistent with the corresponding enzyme assay results. For example, compound MF in binding site 4 with a docking score of $-17.37 \mathrm{Kcal} / \mathrm{mol}$ is lower than that of compound $\mathrm{MJ}(-15.03 \mathrm{Kcal} / \mathrm{mol})$ which is inconsistent with their enzyme inhibition values (13.70 $\mu \mathrm{M}$ for MF and 4.27 $\mu \mathrm{M}$ for MJ). Similar trends were observed in the docking results of binding sites 2 and 5 .

As shown in Figure 7C, binding site 3 was located at two helix structures and the three GCGs showed considerable binding modes based on the docking score and the enzyme inhibition assay. As previous studies have suggested that the helix structure could be 
stabilized by targeting compounds with polyhydroxyl groups, ${ }^{21,23,49}$ our CD results suggest that the helix structures were reduced with increasing concentrations of GA, MF, and MJ. Therefore, this implied that binding site 3 is not targeted by these GCGs.

Binding site 1 is surrounded by coil, bend, and sheet structures, with little helix structures, which contain both active and inactive sites (Figure 7A). The trends of docking score of GA, MF, MJ, and the enzyme assay results are consistent. Based on all of the above analyses, the GCGs, GA, MF, and MJ target the binding site 1 of Saccharomyces cerevisiae $a$ glucosidase. The active site of $a$-glucosidase is comprised of Asp214, Glu276 and Asp349 and is represented by the red oval in Figure 8D. Superimposition of the binding modes of GA, MF, and MJ suggested that all of the binding sites are located at the noncompetitive domain of $a$-glucosidase (Figure 8A, B, and C), which are relatively close to the active site (Figure 8D). All of the docking results demonstrate that GA, MF, and MJ are noncompetitive inhibitors, in accordance with the aforementioned kinetic results (Figure 2).

As shown in Figure 8A, the hydroxyl group of GA can form two hydrogen bonds with the side chain of Ser244 and Phe157. One galloyl group of GA is inserted in the polar area comprised of Arg312, Glu304, Arg439, and Gln350, suggesting that a polar interaction can be formed. Moreover, the phenyl group can form favorable hydrophobic interactions with the side chains of Phe158, Phe157, His239, and His279. Compounds MF and MJ contain more galloyl groups than GA, suggesting that more favorable binding interactions will be formed against a given target according to Ge and coworkers' results. ${ }^{50}$ As shown in Figures 8B and 8C, MF can form four hydrogen bonds with Asp408, Glu304, Ser244, and Phe157, whereas MJ can form eight hydrogen bonds with Glu304, Ser244, Ser299, Glu276, Arg212, Thr215, and Ala216. Thus, hydrogen bonds are formed via the hydroxyl groups of these GCGs. Notably, a similar phenomenon has been observed in other phenolic compounds such as xanthone derivatives, ${ }^{23}$ resveratrol, and oxyresveratrol. ${ }^{21}$ Moreover, more favorable hydrophobic interactions are formed between MF and MJ and $\alpha$-glucosidase residues (Phe157, Phe158, Leu237, His239, His279 Phe300, and Ala278 for MF, and Phe157, Pro309, Leu237, His239, Leu218, His279, and Arg312 for MJ). These hydrophobic sites were occupied by GCGs, suggesting that the GCGs decreased the hydrophobic surface of the enzyme which was consistent with the data obtained from the bis-ANS assay. Also, the binding energy of GA, MF, and MJ is $-10.45,-13.02$, and $-16.35 \mathrm{kcal} / \mathrm{mol}$, respectively, which was in full accordance with results from the enzyme inhibition assay and binding model analyses.

\section{DISCUSSION}

The red maple (Acer rubrum) species is endemic to eastern North America and widely known for its tree sap which is used to produce the natural sweetener, maple syrup. This plant has also been used by the Native Americans as an herbal medicine, and recent phytochemical and biological studies from our group on this species led to the discovery of several GCGs. ${ }^{14-16}$ More importantly, these GCGs show potential as natural AGIs based on in vitro and animal studies. ${ }^{14-16,18}$ While several of these GCGs showed far more potent $a$ glucosidase inhibitory activities than the clinical drug, acarbose, their mechanisms of action 
remained unknown. Herein, we reveal several key mechanisms by which these GCGs interact with $a$-glucosidase.

First, the inhibition type of the GCGs against the $\alpha$-glucosidase enzyme was found to be noncompetitive, suggesting that these gallotannins bind to the specific site of enzymesubstrate complex rather than the enzyme catalytic domain. This binding pattern is in agreement with previous studies of a 'glucose-core containing gallotannin', namely, pentagalloyl glucose (PGG), which is also a noncompetitive $\alpha$-glucosidase inhibitor. ${ }^{51}$ It is noteworthy that this distinguishes the GCGs from acarbose, a synthetic AGI, which is known to be a competitive inhibitor that directly binds to the active site of $a$-glucosidase. ${ }^{52}$ In addition, increasing the number of galloyl groups on the glucitol core enhanced the $a$ glucosidase inhibitory activities of these GCGs, an SAR effect that has also been observed in glucose-core containing gallotannin $a$-glucosidase inhibitors, namely, PGG and its analogs. ${ }^{51}$

Second, ITC analyses revealed that the binding stoichiometry between the GCGs (MF and MJ) and $\alpha$-glucosidase was in a 1:1 ratio suggesting a single binding site for these compounds. This data is similar to that reported for the tea gallotannin, epigallocatechin gallate (EGCG) and lipase. ${ }^{38}$ Additionally, the thermodynamic parameters (Table 2) revealed that the formation of the ligand-enzyme complex was spontaneous and enthalpydriven suggesting that the binding interaction was largely attributed to the hydrogen bonding. This is not surprising since it has been well established that gallotannins form hydrogen bonds with the polar residues of proteins through their galloyl and/or hydroxyl groups. ${ }^{53,54}$ This observation was further supported by our computational models.

Given that gallotannins-protein binding can be enthalpy-driven (by hydrogen bonding and protonation), ${ }^{55-57}$ entropic factors (such as hydrophobic interactions), ${ }^{41}$ are also often involved in the formation of ligand-protein complexes. Therefore, we examined the hydrophobicity of the GCGs and $\alpha$-glucosidase complex.

The GCGs reduced the hydrophobic surface of the enzyme and impeded the formation of the active center of the $a$-glucosidase enzyme. GA, MF, and MJ significantly decreased the $a$ helix conformation of the enzyme protein. Since $\alpha$-helix is a rigid secondary structure that maintains many enzymatic protein functions, loss of this structure may result in enzyme destabilization. Therefore, the major inhibitory mechanism of the GCGs against $a$ glucosidase mainly consists of binding to the enzyme-substrate complex, reducing the hydrophobic surface, and changing the $a$-helix conformation of the enzyme protein.

Lastly, the GCGs act as noncompetitive inhibitors that bind to a noncompetitive domain of $a$-glucosidase located at relatively close to the active site (Figure 7D). This noncompetitive domain is different from the binding pocket of acarbose (competitive inhibitor). ${ }^{52}$ The predicted noncompetitive binding site may provide a novel site for structure-based discovering and designing novel $a$-glucosidase inhibitors. The molecular docking results demonstrate that more galloyl groups in the GCGs leads to enhanced binding affinity against $a$-glucosidase. A major challenge remains for the studies of $a$-glucosidase enzyme chemical steps by multiscale simulation and this methodology has been developed. ${ }^{58}$ Therefore, 
further in silico studies to investigate the aforementioned parameters, as well as multiscale dynamic mechanisms of whether GCGs could trigger the loss of the secondary a-helix of the flexible structures (binding sites of GCGs), is warranted and included in our group's future studies.

Therefore, overall, this study provides useful information on these GCGs which can be used to guide the design of new GCG analogs with superior activities against $a$-glucosidase.

\section{CONCLUSION}

In summary, we have determined the inhibition type of 'glucitol-core containing gallotannins (GCGs)'. The ligand-enzyme interaction was studied using several biophysical and spectroscopic tools including ITC, fluorescent probe and CD spectra. Our results showed that these GCGs had a single binding site, they could decrease the hydrophobic surfaces of the enzyme protein, and also reduce the $\alpha$-helix conformation content of the protein's secondary structure. Our study provides valuable information underlying the interactions between these GCGs and $a$-glucosidase, a crucial step towards further investigating their potential as natural AGIs. Further investigation of these GCGs will focus on in vivo studies to evaluate their safety and efficacy as potential dietary agents for T2DM management which is included in our group's future planned studies.

\section{Supplementary Material}

Refer to Web version on PubMed Central for supplementary material.

\section{Acknowledgments}

HM was financially supported by the Omar Magnate Foundation Fellowship. The spectroscopic data were acquired from instruments located in the RI-INBRE core facility obtained from Grant \# P20RR016457 from the National Center for Research Resources (NCRR), a component of the National Institutes of Health (NIH) and the Marine Science Research Facility, supported by NSF-EPSCoR (NSF-1004057) and URI.

\section{References}

1. Dwek RA, Butters TD. Chem Rev. 2002; 102:283-284.

2. Jacob GS. Curr Opin Struct Biol. 1995; 5:605-611. [PubMed: 8574695]

3. Ghazarian H, Idoni B, Oppenheimer SB. Acta Histochem. 2011; 113:236-247. [PubMed: 20199800]

4. Lebovitz HE. Endocrinol Metab Clin North Am. 1997; 26:539-551. [PubMed: 9314014]

5. Scheen AJ. Drugs. 1997; 54:355-368. [PubMed: 9279500]

6. van de Laar FA. Vasc Health Risk Manag. 2008; 4:1189-1195. [PubMed: 19337532]

7. van de Laar FA, Lucassen PL, Akkermans RP, van de Lisdonk EH, Rutten GE, van Weel C. Diabetes Care. 2005; 28:154-163. [PubMed: 15616251]

8. Martin AE, Montgomery PA. Am J Health Syst Pharm. 1996; 53:2277-2290. [PubMed: 8893066]

9. Kumar S, Narwal S, Kumar V, Prakash O. Pharmacogn Rev. 2011; 5:19-29. [PubMed: 22096315]

10. Li L, Seeram NP. J Agric Food Chem. 2010; 58:11673-11679. [PubMed: 21033720]

11. Bate-Smith EC. Phytochemistry. 1977; 16:1421-1426.

12. Haddock EA, Gupta RK, Al-Shafi SMK, Haslam E, Magnolato D. J Chem Soc, Perkin Trans 1. 1982:2515-2524.10.1039/P19820002515

13. Hatano T, Hattori S, Ikeda Y, Shingu T, Okuda T. Chem Pharm Bull. 1990; 38:1902-1905. 
14. Wan C, Yuan T, Li L, Kandhi V, Cech NB, Xie M, Seeram NP. Bioorg Med Chem Lett. 2012; 22:597-600. [PubMed: 22079755]

15. Yuan T, Wan C, Liu K, Seeram NP. Tetrahedron. 2012; 68:959-964.

16. Zhang Y, Ma H, Yuan T, Seeram NP. Nat Prod Commun. 2015; 10:1409-1412. [PubMed: 26434129]

17. Ogawa A, Miyamae Y, Honma A, Koyama T, Yazawa K, Shigemori H. Chem Pharm Bull. 2011; 59:672-675. [PubMed: 21532209]

18. Seeram NP, Xu J, Li L, Slitt A. Med Health R I. 2012; 95:283. [PubMed: 23094425]

19. Ren Y, Himmeldirk K, Chen X. J Med Chem. 2006; 49:2829-2837. [PubMed: 16640344]

20. Samulitis B, Goda T, Lee S, Koldovský O. Drugs Exp Clin Res. 1986; 13:517-524. [PubMed: 2962844]

21. He H, Lu YH. J Agric Food Chem. 2013; 61:8110-8119. [PubMed: 23909841]

22. Yuan T, Wan C, Ma H, Seeram NP. Planta Med. 2013; 79:1674-1679. [PubMed: 24108434]

23. Liu Y, Ma L, Chen WH, Park H, Ke Z, Wang B. J Phys Chem B. 2013; 117:13464-13471. [PubMed: 24083955]

24. Jeoh T, Baker JO, Ali MK, Himmel ME, Adney WS. Anal Biochem. 2005; 347:244-253. [PubMed: 16269126]

25. Liu M, Zhang W, Qiu L, Lin X. J Biochem. 2011; 149:27-33. [PubMed: 20870646]

26. Liu M, Yin H, Liu G, Dong J, Qian Z, Miao J. J Agric Food Chem. 2014; 62:5548-5554. [PubMed: 24897556]

27. Whitmore L, Wallace BA. Biopolymers. 2008; 89:392-400. [PubMed: 17896349]

28. Lobley A, Whitmore L, Wallace B. Bioinformatics. 2002; 18:211-212. [PubMed: 11836237]

29. Yamamoto K, Miyake H, Kusunoki M, Osaki S. FEBS J. 2010; 277:4205-4214. [PubMed: 20812985]

30. Wang L, Gu Q, Zheng X, Ye J, Liu Z, Li J, Hu X, Hagler A, Xu J. J Chem Inf Model. 2013; 53:2409-2422. [PubMed: 23901876]

31. Dong YN, Wang L, Gu Q, Chen H, Liu X, Song Y, Chen W, Hagler AT, Zhang H, Xu J. Mol Divers. 2013; 17:371-382. [PubMed: 23585056]

32. Salomon-Ferrer R, Case DA, Walker RC. Wiley Interdiscip Rev: Comput Mol Sci. 2013; 3:198210.

33. Hornak V, Abel R, Okur A, Strockbine B, Roitberg A, Simmerling C. Proteins. 2006; 65:712-725. [PubMed: 16981200]

34. de Souza ON, Ornstein RL. J Biomol Struct Dyn. 1997; 14:607-611. [PubMed: 9130082]

35. Abid, O-u-R.; Babar, TM.; Ali, FI.; Ahmed, S.; Wadood, A.; Rama, NH.; Uddin, R.; Zaheer ul, H.; Khan, A.; Choudhary, MI. ACS Med Chem Lett. 2010; 1:145-149. [PubMed: 24900188]

36. Corbeil CR, Williams CI, Labute P. J Comput Aided Mol Des. 2012; 26:775-786. [PubMed: 22566074]

37. Yoshimizu M, Tajima Y, Matsuzawa F, Aikawa SI, Iwamoto K, Kobayashi T, Edmunds T, Fujishima K, Tsuji D, Itoh K, Ikekita M, Kawashima I, Sugawara K, Ohyanagi N, Suzuki T, Togawa T, Ohno K, Sakuraba H. Clin Chim Acta. 2008; 391:68-73. [PubMed: 18328816]

38. Wu X, He W, Yao L, Zhang H, Liu Z, Wang W, Ye Y, Cao J. J Agric Food Chem. 2013; 61:8829_ 8835. [PubMed: 23971865]

39. Frazier RA, Papadopoulou A, Green RJ. J Pharm Biomed Anal. 2006; 41:1602-1605. [PubMed: 16522360]

40. Ross PD, Subramanian S. Biochemistry. 1981; 20:3096-3102. [PubMed: 7248271]

41. Oh HI, Hoff JE, Armstrong GS, Haff LA. J Agric Food Chem. 1980; 28:394-398.

42. Kilmister RL, Faulkner P, Downey MO, Darby SJ, Falconer RJ. Food Chem. 2016; 190:173-178. [PubMed: 26212957]

43. McClure WO, Edelman GM. Biochemistry. 1966; 5:1908-1919. [PubMed: 4164420]

44. Brand L, Gohlke JR. Annu Rev Biochem. 1972; 41:843-868. [PubMed: 4563443]

45. Borejdo J. Biochemistry. 1983; 22:1182-1187. [PubMed: 6838846]

46. Yan J, Zhang G, Pan J, Wang Y. Int J Biol Macromol. 64:213-223. [PubMed: 24333230] 
47. Du ZY, Liu RR, Shao WY, Mao XP, Ma L, Gu LQ, Huang ZS, Chan ASC. Eur J Med Chem. 2006; 41:213-218. [PubMed: 16387392]

48. Shen Q, Shao J, Peng Q, Zhang W, Ma L, Chan ASC, Gu L. J Med Chem. 2010; 53:8252-8259. [PubMed: 21053896]

49. Liu M, Zhang W, Wei J, Lin X. Marine Drugs. 2011; 9:1554-1565. [PubMed: 22131958]

50. Ge H, Liu G, Xiang YF, Wang Y, Guo CW, Chen NH, Zhang YJ, Wang YF, Kitazato K, Xu J. PLoS One. 2014; 9:e94392. [PubMed: 24718639]

51. Gao H, Huang YN, Xu PY, Kawabata J. Food Chem. 2007; 105:628-634.

52. Calder PC, Geddes R. Carbohydr Res. 1989; 191:71-78. [PubMed: 2776140]

53. Poncet-Legrand C, Gautier C, Cheynier V, Imberty A. J Agric Food Chem. 2007; 55:9235-9240. [PubMed: 17850090]

54. Frazier RA, Papadopoulou A, Mueller-Harvey I, Kissoon D, Green RJ. J Agric Food Chem. 2003; 51:5189-5195. [PubMed: 12926857]

55. Luck G, Liao H, Murray NJ, Grimmer HR, Warminski EE, Williamson MP, Lilley TH, Haslam E. Phytochemistry. 1994; 37:357-371. [PubMed: 7765619]

56. Charlton AJ, Baxter NJ, Lilley TH, Haslam E, McDonald CJ, Williamson MP. FEBS Lett. 1996; 382:289-292. [PubMed: 8605987]

57. Spencer CM, Cai Y, Martin R, Gaffney SH, Goulding PN, Magnolato D, Lilley TH, Haslam E. Phytochemistry. 1988; 27:2397-2409.

58. Frushicheva MP, Cao J, Warshel A. Biochemistry. 2011; 50:3347-3355. 


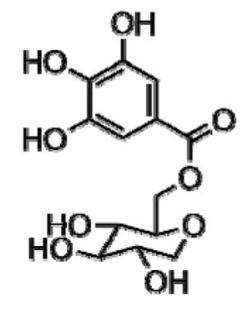

ginnalin B (GB)

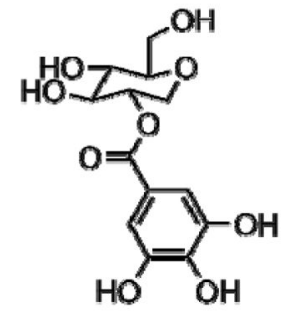

ginnalin C (GC)

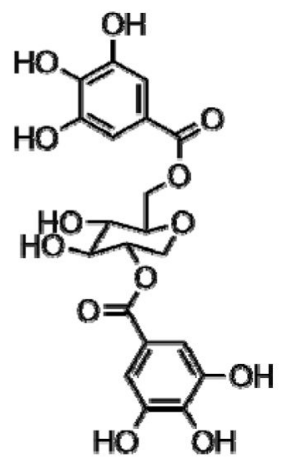

ginnalin A (GA)<smiles>O=C(OCC1(CO)COC(OC(=O)c2cc(O)c(O)c(O)c2)C(O)CO1)c1cc(O)c(O)c(O)c1</smiles>

maplexin F (MF)<smiles></smiles>

maplexin J (MJ)

Figure 1.

Chemical structures of five 'glucitol core containing gallotannins (GCGs)' : ginnalin A, ginnalin $\mathrm{B}$, ginnalin $\mathrm{C}$, maplexin $\mathrm{F}$ and maplexin $\mathrm{J}$. 

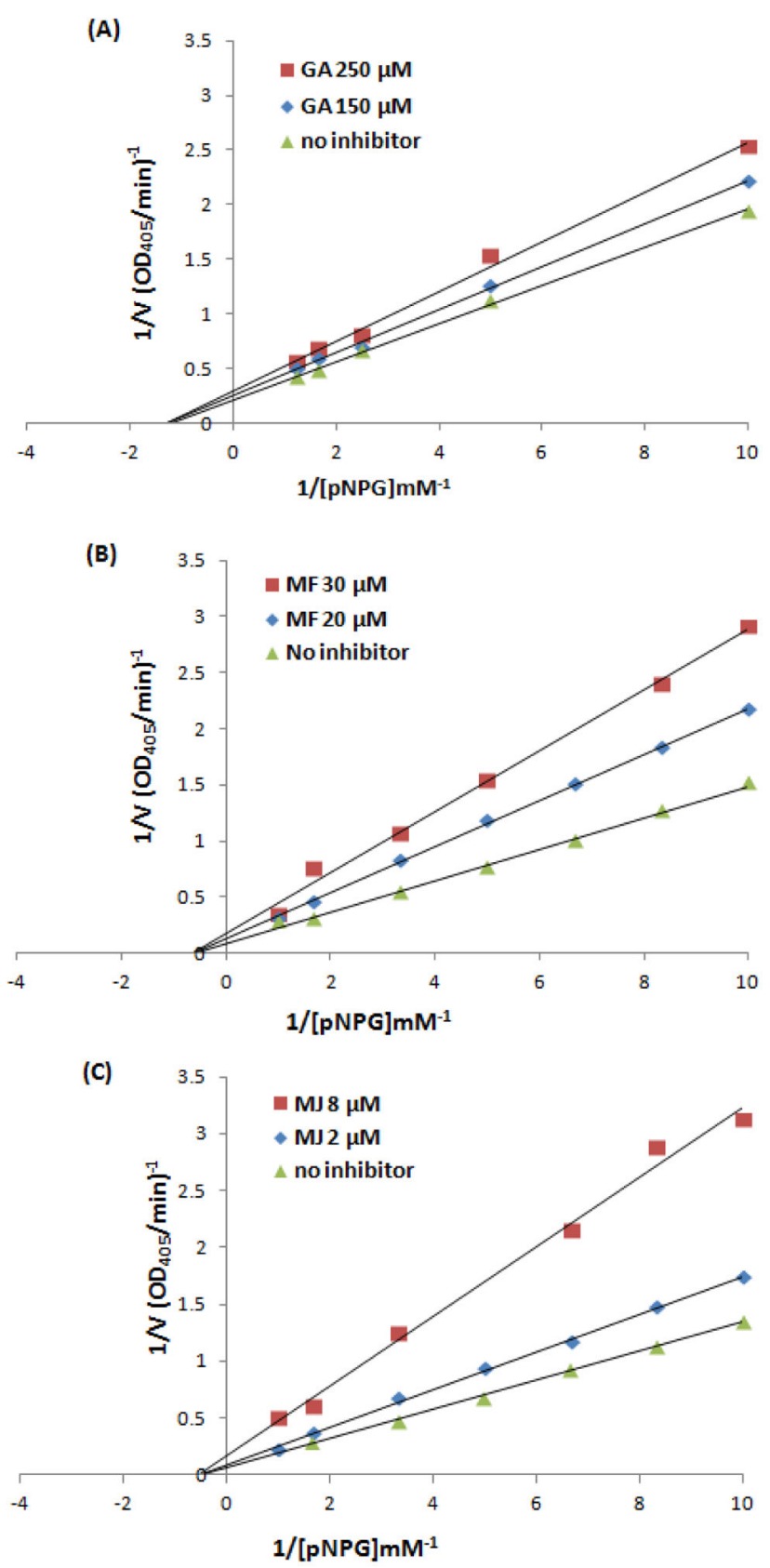

Figure 2.

Lineweaver-Burk plots of the kinetics of inhibition of GA (A), MF (B) and MJ (C) on $a$ glucosidase enzyme. Two concentrations (ranging from $2-250 \mu \mathrm{M}$ of ligands; close to their $\mathrm{IC}_{50}$ values) were co-incubated with $a$-glucosidase at $37^{\circ} \mathrm{C}$ for $30 \mathrm{~min}$, then pNPG was added at varying concentrations (from $1-1000 \mu \mathrm{M}$ ). 
(A)

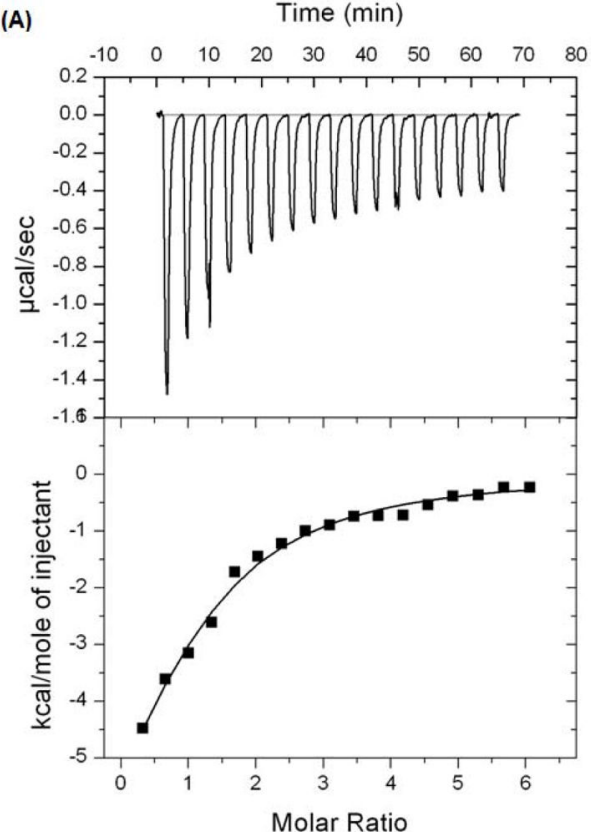

(B) Time $(\mathrm{min})$

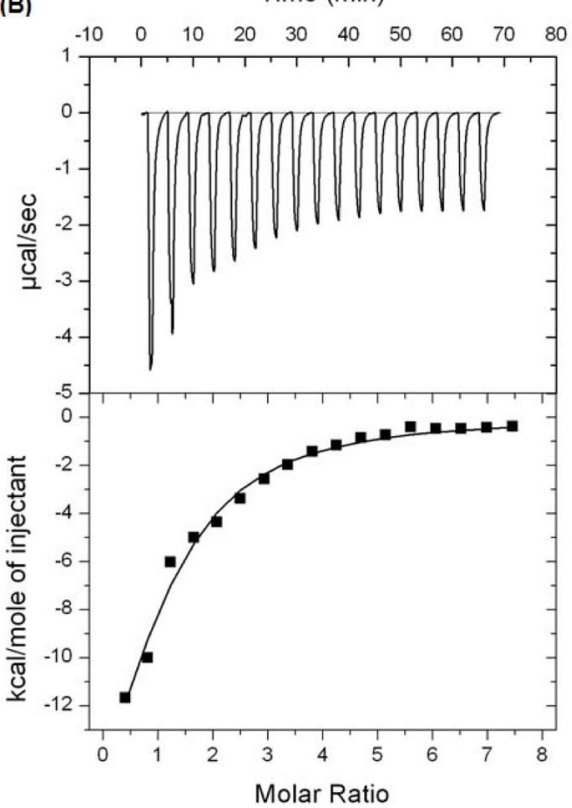

Figure 3.

Results of isothermal titration calorimetry (ITC) for GCGs binding to $a$-glucosidase: (Top) Raw data plot of heat flow against time for the titration of MF (A) or MJ (B) into $0.031 \mathrm{mM}$ $a$-glucosidase enzyme protein. (Bottom) Plot of molar enthalpy change against GCGs/ $a$ glucosidase enzyme molar ratio. 

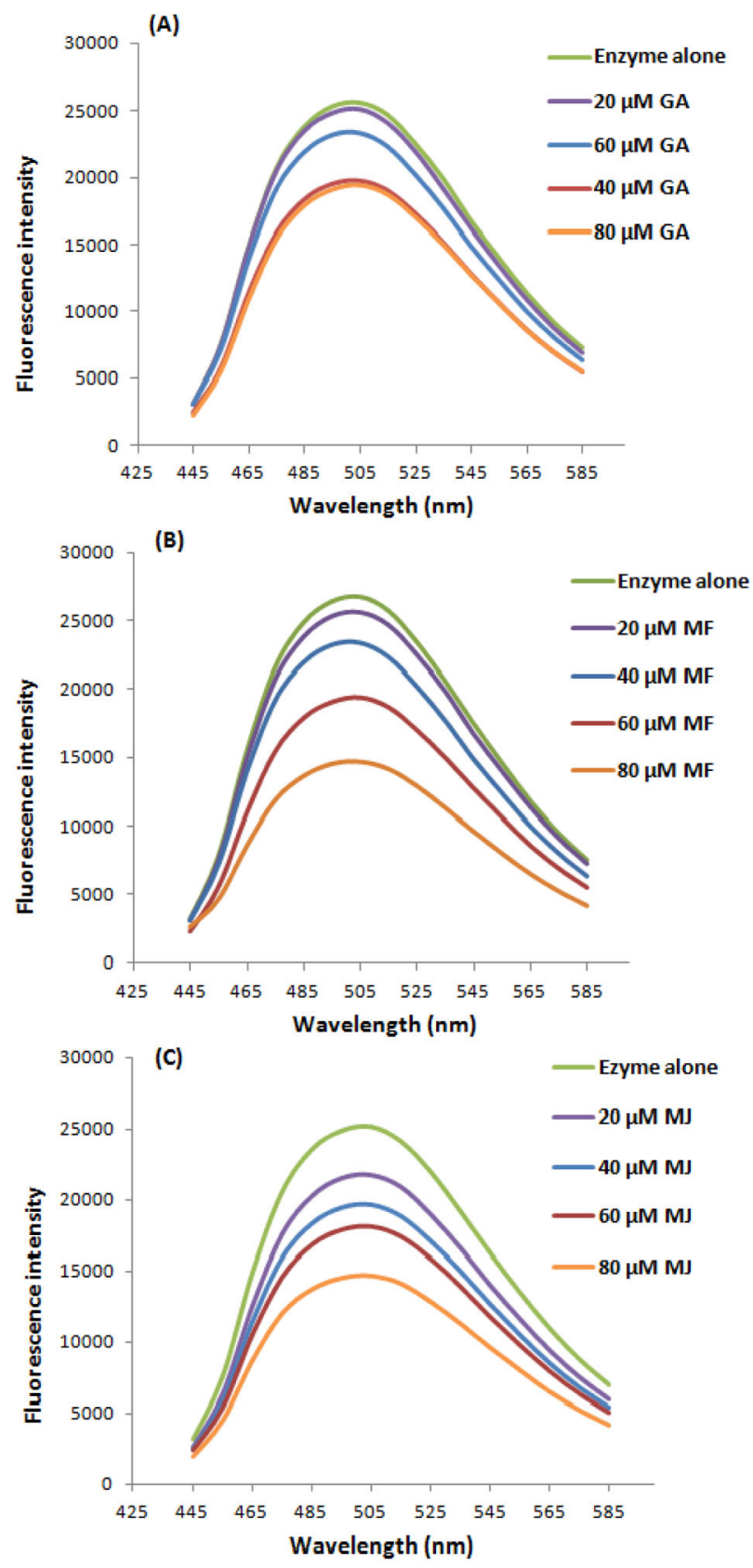

Figure 4.

Fluorescence intensity of bis-ANS- $\alpha$-glucosidase complex. The changes of fluorescence intensity were induced by GA (A), MF (B) and MJ (C) at different concentrations ranging from $20-80 \mu \mathrm{M}$. 

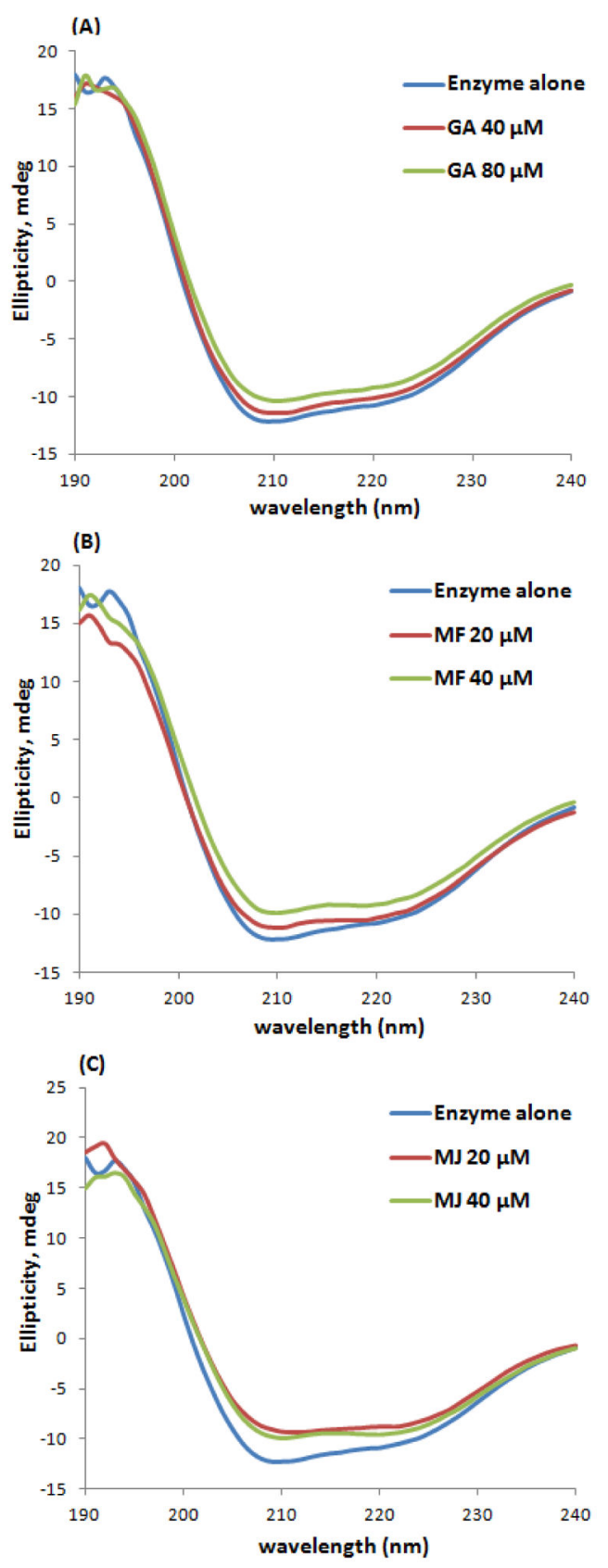

Figure 5.

Circular dichroism (CD) spectra of the $\alpha$-glucosidase-GCG complex. $\alpha$-glucosidase ( $2 \mu \mathrm{M})$ were co-incubated with $\mathrm{GA}, \mathrm{MF}$, or $\mathrm{MJ}$ at $20-80 \mu \mathrm{M}$ at $37^{\circ} \mathrm{C}$ for $20 \mathrm{~min}$. 

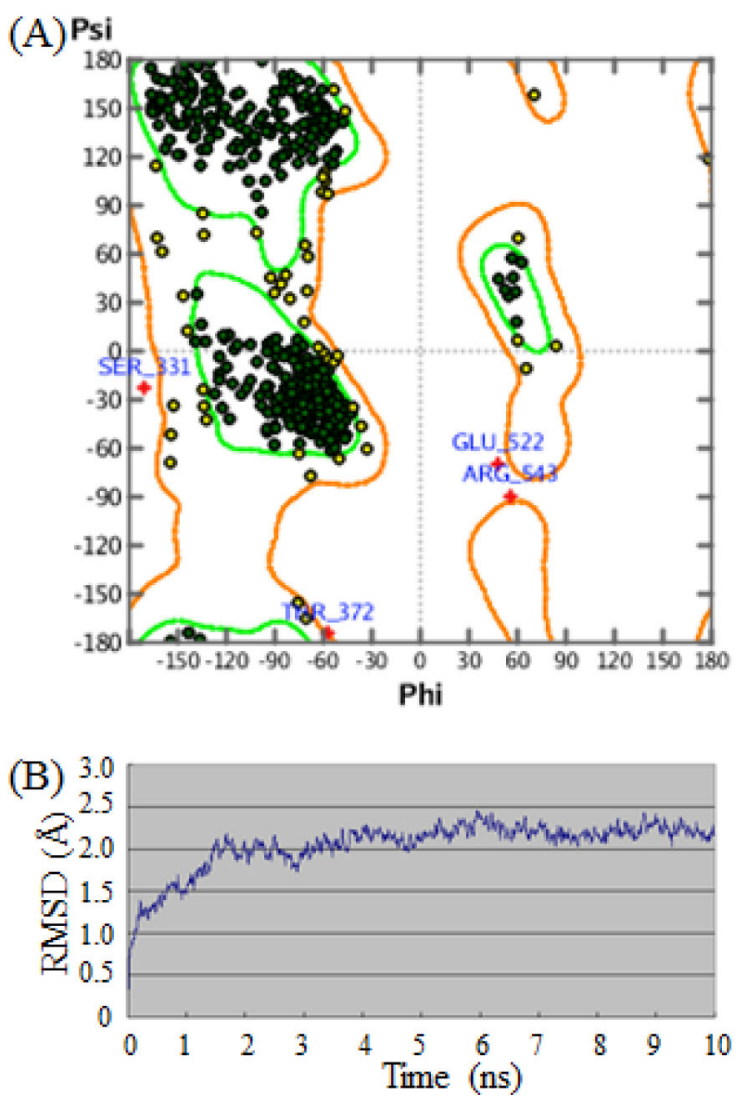

Figure 6.

The properties of the refined $a$-glucosidase structure. (A) Ramachandran plot for a 3D model of a-glucosidase (residues denoted with a + are outliers); (B) Time dependences of the root mean square deviations (RMSD) of the backbone atoms (Ca, N, O-atoms) with respect to initial structure. 

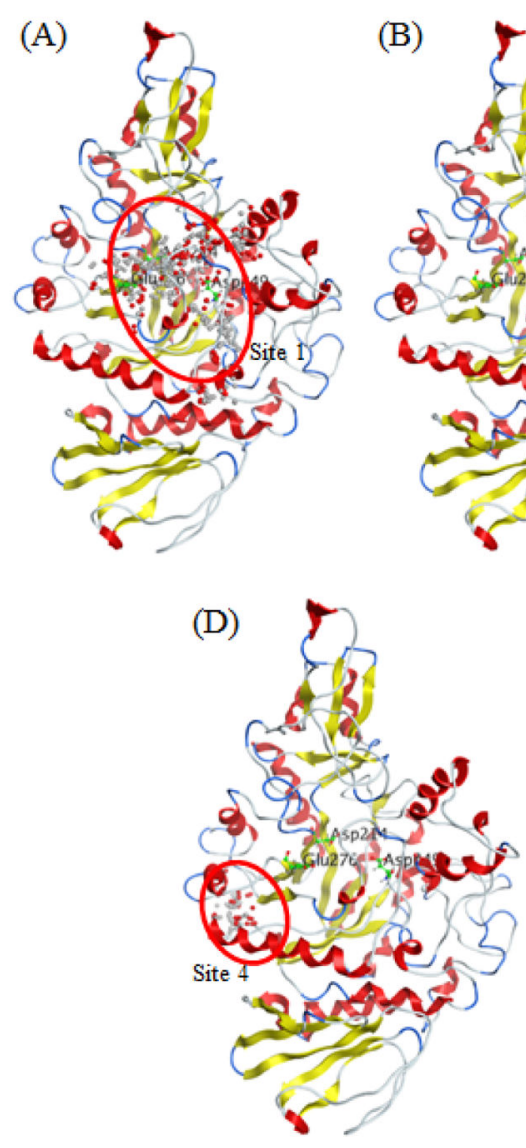
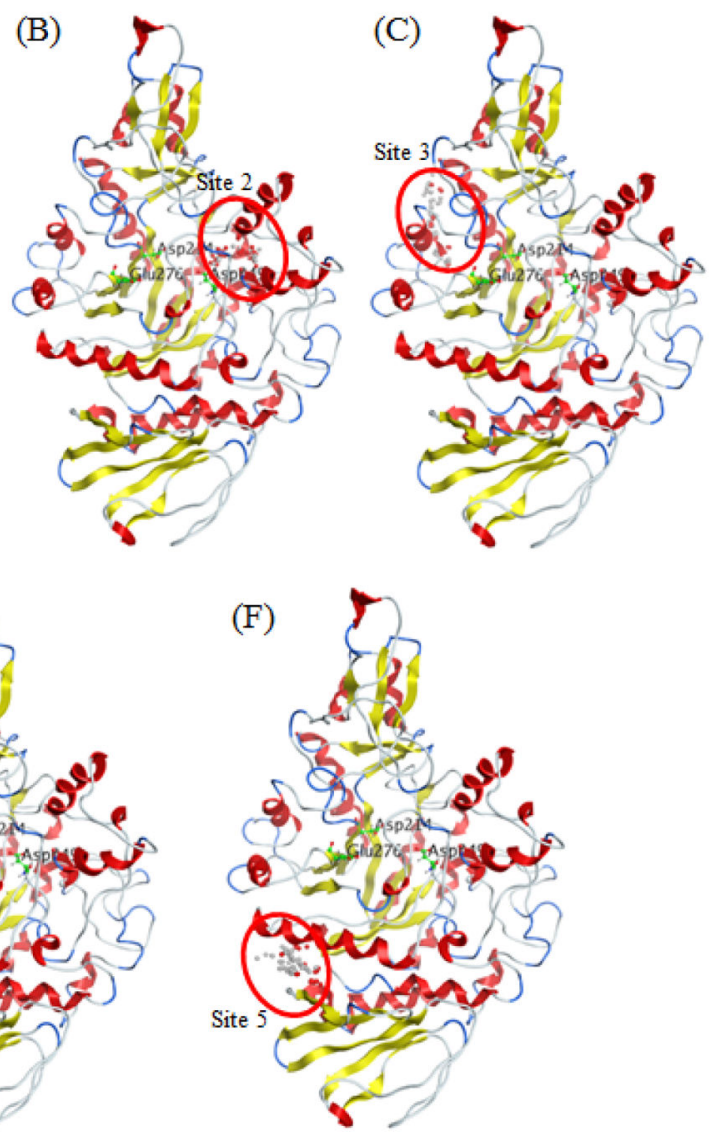

Figure 7.

Top five potential ligand binding site generated via Site Finder module in MOE2010.10. The binding site is represented by alpha sphere centers and red oval. The active site is comprised of catalytic residues (Asp 214, Glu276, and Asp349). 

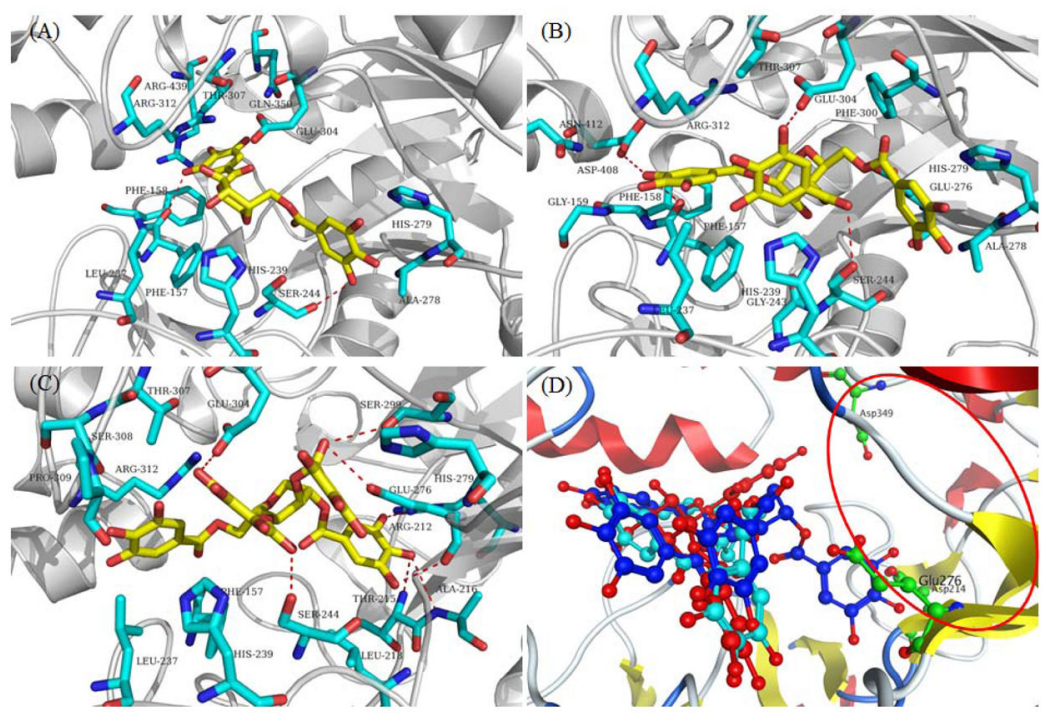

Figure 8.

Binding modes for GA (A), MF (B), MJ (C), and superimposition of the binding modes of GA (red), MF (aquamarine blue), and MJ (blue). Hydrogen bonds are depicted by red dotted lines. Red oval represents the active binding site. 


\section{Table 1}

a-Glucosidase inhibitory activities of GCGs

\begin{tabular}{|c|c|c|c|}
\hline Compound & \# of galloyl group & $\mathrm{IC}_{50}(\mu \mathrm{M}){ }^{a}$ & Type of inhibition \\
\hline ginnalin B (GB) & 1 & $>1000$ & n.d. \\
\hline ginnalin C (GC) & 1 & $>1000$ & n.d. \\
\hline ginnalin A (GA) & 2 & $216.43 \pm 3.19$ & noncompetitive \\
\hline maplexin F (MF) & 3 & $13.70 \pm 0.87$ & noncompetitive \\
\hline maplexin J (MJ) & 4 & $4.27 \pm 0.13$ & noncompetitive \\
\hline acarbose $b$ & - & $142.40 \pm 1.68$ & competitive \\
\hline
\end{tabular}

${ }^{a}$ IC50 values are shown as mean \pm S.D. from three independent experiments;

${ }^{b}$ Positive control; n.d. $=$ not determined. 


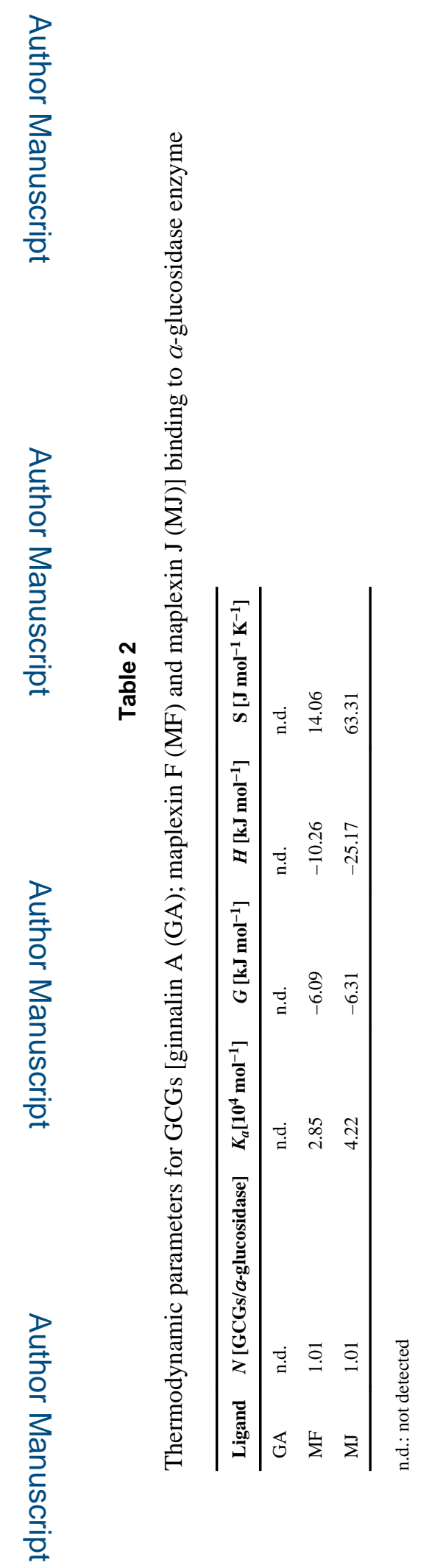

RSC Adv. Author manuscript; available in PMC 2016 March 15. 
Table 3

The effect of GCGs (GA, MF, and MJ) on the secondary structure of $a$-glucosidase enzyme

\begin{tabular}{lllll}
\hline Ligands (Conc.) & a-Helix \% & $\beta$-Fold \% & $\beta$-Turns \% & Unordered \% \\
\hline Control & 36.3 & 21.9 & 14.3 & 26.9 \\
GA $40 \mu \mathrm{M}$ & 37.8 & 22.7 & 11.5 & 27.8 \\
GA $80 \mu \mathrm{M}$ & 33.5 & 22.5 & 15.8 & 27.7 \\
MF $20 \mu \mathrm{M}$ & 30.7 & 24.7 & 15.6 & 28.4 \\
MF $40 \mu \mathrm{M}$ & 31.2 & 22.7 & 16.6 & 28.9 \\
MJ $20 \mu \mathrm{M}$ & 31.8 & 21.1 & 20.4 & 26.4 \\
MJ 40 $\mu \mathrm{M}$ & 30.7 & 24.4 & 19.1 & 25.3 \\
\hline
\end{tabular}

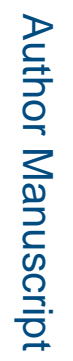

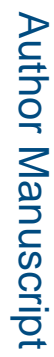




\section{Table 4}

Detailed docking results for GA, MF, and MJ. Cluster represents the docking score of the lowest binding energy conformation of the more populated cluster.

\begin{tabular}{ccccc}
\hline \multicolumn{2}{c}{ compound } & GA & MF & MJ \\
\hline Site 1 & Range & $(-17.59,-8.53)$ & $(-19.87,-11.98)$ & $(-21.70,-9.40)$ \\
& cluster & -10.54 & -12.02 & -16.53 \\
Site 2 & Range & $(-12.57,-5.78)$ & $(-12.56,-6.80)$ & $(-13.77,-6.39)$ \\
& cluster & -8.44 & -8.15 & -9.14 \\
Site 3 & Range & $(-16.11,-6.47)$ & $(-18.20,-8.70)$ & $(-19.47,-7.70)$ \\
& cluster & -11.27 & -12.25 & -13.04 \\
Site 4 & Range & $(-14.41,-5.28)$ & $(-17.37,-6.43)$ & $(-15.03,-5.90)$ \\
& cluster & -10.26 & -10.37 & -9.86 \\
Site 5 & Range & $(-15.24,-7.46)$ & $(-17.78,-6.23)$ & $(-16.00,-7.53)$ \\
& cluster & -11.32 & -11.72 & -11.06 \\
\hline
\end{tabular}

